OPEN ACCESS

Edited by:

Giovane R. Sousa,

Harvard Medical School,

United States

Reviewed by:

Ulrike Kemmerling,

University of Chile, Chile

Núria Gironès,

Severo Ochoa Molecular Biology

Center (CSIC-UAM), Spain

*Correspondence:

Paulo Marcos Matta Guedes pauloguedes@cb.ufrn.br

Specialty section:

This article was submitted to

Parasite and Host,

a section of the journal

Frontiers in Cellular and

Infection Microbiology

Received: 17 April 2021 Accepted: 25 June 2021

Published: 15 July 2021

Citation:

Queiroga TBD, Pereira NdS,

Silva DDd, Andrade CaM, Araújo Júnior RFd, Brito CRdN,

Galvão LMdC, Câmara ACJd,

Nascimento MSL and Guedes PMM (2021) Virulence of Trypanosoma

cruzi Strains is Related to the Differential Expression of Innate Immune Receptors in the Heart. Front. Cell. Infect. Microbiol. 11:696719.

doi: 10.3389/fcimb.2021.696719

\section{Virulence of Trypanosoma cruzi Strains Is Related to the Differential Expression of Innate Immune Receptors in the Heart}

Tamyres Bernadete Dantas Queiroga ${ }^{1}$, Nathalie de Sena Pereira ${ }^{2}$, Denis Dantas da Silva ${ }^{1}$, Cléber de Mesquita Andrade ${ }^{3}$, Raimundo Fernandes de Araújo Júnior ${ }^{4}$, Carlos Ramon do Nascimento Brito ${ }^{5}$, Lúcia Maria da Cunha Galvão ${ }^{5}$, Antônia Cláudia Jácome da Câmara ${ }^{5}$, Manuela Sales Lima Nascimento ${ }^{6}$ and Paulo Marcos Matta Guedes ${ }^{6 *}$

\footnotetext{
${ }^{1}$ Graduate Program Parasitary Biology, Federal University of Rio Grande do Norte, Natal, Brazil, ${ }^{2}$ Graduate Program Health and Biological Sciences, Federal University of Vale do São Francisco, Petrolina, Brazil, ${ }^{3}$ Department of Biomedical Sciences, Rio Grande do Norte State University, Natal, Brazil, ${ }^{4}$ Laboratory of Investigation of the Inflammation and Cancer (LAICI)/ Department of Morphology, Federal University of Rio Grande do Norte, Natal, Brazil, ${ }^{5}$ Department of Clinical and Toxicological Analyses, Federal University of Rio Grande do Norte, Natal, Brazil, ${ }^{6}$ Department of Microbiology and Parasitology, Federal University of Rio Grande do Norte, Natal, Brazil
}

Resistance or susceptibility to $T$. cruzi infection is dependent on the host immunological profile. Innate immune receptors, such as Toll-like receptors (TLRs/TLR2, TLR4, TLR7, and TLR9) and Nod-like receptors (NLRs/NOD1 and NLRP3 inflammasome) are involved with the resistance against acute experimental T. cruzi infection. Here, we evaluated the impact of $T$. cruzi virulence on the expression of innate immune receptors and its products in mice. For that, we used six T. cruzi strains/isolates that showed low (AM64/TclV and 3253/Tc-V), medium (PL1.10.14/Tclll and CL/TcVI), or high (Colombian/Tc-I and Y/Tcll) virulence and pathogenicity to the vertebrate host and belonging to the six discrete typing units (DTUs) - Tcl to TcVI. Parasitemia, mortality, and myocarditis were evaluated and correlated to the expression of TLRs, NLRs, adapter molecules, cytokines, and iNOS in myocardium by real time PCR. Cytokines (IL-1 $\beta, \mathrm{IL}-12, \mathrm{TNF}-\alpha$, and IFN- $\gamma$ ) were quantified in sera 15 days after infection. Our data indicate that high virulent strains of $T$. cruzi, which generate high parasitemia, severe myocarditis, and 100\% mortality in infected mice, inhibit the expression of TLR2, TLR4, TLR9, TRIF, and Myd88 transcripts, leading to a low IL-12 production, when compared to medium and low virulent T. cruzi strains. On the other hand, the high virulent $T$. cruzi strains induce the upregulation of NLRP3, caspase-1, IL$1 \beta$, TNF- $\alpha$, and iNOS mRNA in heart muscle, compared to low and medium virulent strains, which may contribute to myocarditis and death. Moreover, high virulent strains induce higher levels of IL-1 $\beta$ and TNF- $\alpha$ in sera compared to less virulent parasites. Altogether the data indicate that differential TLR and NLR expression in heart muscle is correlated with virulence and pathogenicity of $T$ cruzi strains. A better knowledge of the immunological mechanisms involved in resistance to $T$. cruzi infection is important to 
understand the natural history of Chagas disease, can lead to identification of immunological markers and/or to serve as a basis for alternative therapies.

Keywords: NLRP3 inflammasome, Toll-like receptor, Nod-like receptor, mice, Trypanosoma cruzi, innate immune receptors, virulence

\section{INTRODUCTION}

The experimental infection of mice with different strains of Trypanosoma cruzi (T. cruzi) can range from asymptomatic to lethal infections. The susceptibility or resistance is determined by characteristics inherent to the parasite and host. Tropism, virulence, inoculation, and genetics are important characteristics of the parasite (Dias et al., 2000; Guedes et al., 2007; Gutierrez et al., 2009). T. cruzi strains are grouped in seven discrete type units (DTU) TcI-TcVI and TcBat, which present great variability in virulence and pathogenicity in the vertebrate host (Zingales et al., 2009; Zingales et al., 2012; Zingales, 2018).

Initial activation of immune response against T. cruzi occurs through the recognition of molecular patterns present in parasites by pattern recognition receptors (PRRs) (Bartholomeu et al., 2008; Oliveira et al., 2010; Rodrigues et al., 2012). Toll-like receptors (TLRs) and Nod-like receptors (NLRs) are important PRRs and play a fundamental role in modulating the immune response against T. cruzi (Dutra et al., 1994; Teixeira et al., 2002; Gomes et al., 2003). Several T. cruzi molecules have been identified as TLR agonists, such as, glycosylphosphatidinositol (GPI) which anchors activating TLR2 (Campos et al., 2001); glycoinositolphospholipid (GIPL) which induces the NF- $\kappa \mathrm{B}$ (nuclear factor- $\kappa \mathrm{B}$ ) via TLR4 activation (Oliveira et al., 2004); RNA and DNA which can induce the activation of TLR7 and TLR9 (Koga et al., 2006; Caetano et al., 2011). The molecules present in T. cruzi that would be NLR agonists have not been identified yet. Parasite is recognized by different receptors and will be phagocytosed by macrophages, leading to the production of inflammatory cytokines such as interleukin-12 (IL-12) (Silva et al., 1995; Aliberti et al., 1996), which acts on natural killer (NK) cells, activating the production of more IL-12 and IFN- $\gamma$. The IFN- $\gamma$ (Silva et al., 1992; Abrahamsohn and Coffman, 1996) produced, together with tumor necrosis factor alpha (TNF- $\alpha$ ) (Silva et al., 1995; Bahia-Oliveira et al., 1998), activates the enzyme inducible nitric oxide synthase (iNOS), leading to nitric oxide (NO) synthesis, which acts to limit the intracellular multiplication of the parasite (Reis et al., 1997). On the other hand, cytokines, such as IL-10 and TGF- $\beta$ inhibit iNOS, restricting the inflammation but allowing parasite replication (Silva et al., 1991; Holscher et al., 1998).

Trypanosoma cruzi experimental infection in TLR-deficient mice showed that TLR2 (Bafica et al., 2006), TLR4 (Oliveira et al., 2010), TLR7 (Caetano et al., 2011), and TLR9 (Bartholomeu et al., 2008) play a role in host resistance (Oliveira et al., 2010; Rodrigues et al., 2012). Some receptors, such as TLR2 and TLR9, act synergistically in helping to control the infection (Bafica et al., 2006). TLR3 does not appear to be involved in resistance in experimental models (Caetano et al., 2011), but TRIF $^{-/-}$and $\mathrm{MyD}^{-/-}$mice exhibit increased parasitism and mortality to
T. cruzi infection (Campos and Gazzinelli, 2004; Koga et al., 2006; Bafica et al., 2006; Oliveira et al., 2010). Bone marrowderived macrophages from NOD1 knockout mice exhibited reductions in NF- $\kappa \mathrm{B}$ and its products, failing to control the parasite even in the presence of IFN- $\gamma$ (Silva et al., 2010). NLRP3 inflammasome is also important in resistance to T. cruzi infection (Silva et al., 2013).

Although the role of TLRs and NLRs in murine T. cruzi infection is clear, the influence of $T$. cruzi strains with different virulence and pathogenicity profiles on the expression of these molecules and on the modulation of the host immune response leading to asymptomatic infection or mortality is still unknown. Here we showed that the increase in virulence of T. cruzi strains is related to TLR2, TLR4, TLR9, TRIF, and Myd88 inhibition and NLRP3, caspase-1, IL-1 $\beta$, TNF- $\alpha$ overexpression. A better understanding of the immunological mechanisms involved in the resistance to different strains of $T$. cruzi can lead to the identification of immunological markers and serve as a basis for therapies and prophylaxis studies.

\section{MATERIALS AND METHODS}

\section{Biosecurity, Animals, and Ethics Statement}

All experiments were conducted according to the standard biosafety and institutional security procedures established by the Internal Biosafety Commission of the Federal University of Rio Grande do Norte (CIBio-UFRN).

Male Swiss Webster mice, 6-8 weeks old, were cared for according to institutional ethical guidelines and the Ethics Committee on Animal Use (CEUA) of the Federal University of Rio Grande do Norte (UFRN). All experiments were previously approved by protocol number 017/2012 CEUA/UFRN.

Ten animals for each T. cruzi strain were used for parasitemia and mortality. Another 10 animals for each group were used to determine myocarditis and cardiac parasitism, to quantify innate immunity receptors and cytokines in the myocardium by PCR, and to evaluate the levels of seric cytokines. Uninfected control group was also composed of 10 mice. Experiments were carried out in duplicate.

\section{Parasites and Infection}

Mice were infected intraperitoneally with $1 \times 10^{4}$ trypomastigote blood forms of T. cruzi strains/isolates belonging to the six genetic groups (Discrete Typing Units-DTU): Colombian-TcI, isolated from blood culture from a human case in Colombia (Federici et al., 1964); Y-TcII, isolated from an acute case of human Chagas disease in city of Marilia, state of Sao Paulo, Brazil 
(Silva and Nussenzweig, 1953); PL 1.10.14-TcIII, isolated by xenoculture of a Panstrongylus lutzi in Serra Negra do Norte, state of Rio Grande do Norte, Brazil (Martins et al., 2015); AM64$\mathrm{TcIV}$, isolated from a patient in acute phase, state of Amazonas, Brazil (Teston et al., 2013); 3253-TcV, isolated from a human case in the state of Rio Grande do Norte, Brazil (Martins et al., 2015); and CL-TcVI, isolated from Triatoma infestans found naturally infected in the state of Rio Grande do Sul, Brazil (Brener and Chiari, 1963).

Blood trypomastigote forms of all T. cruzi strains used in this research were frozen in liquid nitrogen $\left(-196^{\circ} \mathrm{C}\right)$, defrosted, inoculated, and maintained for five successive passages in Swiss mice prior to the experiments. All strains were obtained at the Laboratory of Biology of Trypanosoma cruzi and Chagas disease at the Federal University of Rio Grande do Norte-UFRN coordinated by professor AC. The AM-64 strain was previously obtained from Professor Max Jean de Ornelas Toledo at the Maringa State University (UEM) and the Colombian, Y, and CL strains were previously obtained from Professor Egler Chiari at the Federal University of Minas Gerais (UFMG). The PL 1.10.14 and 3253 strains were isolated by the laboratory of the Biology of Trypanosoma cruzi and Chagas disease-UFRN.

\section{Parasitemia, Survival, and Myocarditis}

The parasitemia was performed using Prager (1952) and Pizzi (1953) methods modified by Brener (1962). Parasitemia was determined microscopically by examining daily the fresh blood from the tail vein of mice infected with high virulent strains (Colombian $/ \mathrm{n}=10$ and $\mathrm{Y} / \mathrm{n}=10$ ), medium virulent strains $(\mathrm{PL}$ $1.10 .14 / \mathrm{n}=10$ and $\mathrm{CL} / \mathrm{n}=10)$, low virulent strains $(3252 / \mathrm{n}=10$ and $A M 64 / \mathrm{n}=10$ ) from day 5 post infection during 30 days. Animal survival was monitored daily for 60 days post infection.

Myocarditis and cardiac parasitism were determined in animals infected with high virulent strains (Colombian/n $=5$ and $\mathrm{Y} / \mathrm{n}=5)$, medium virulent strains (PL $1.10 .14 / \mathrm{n}=5$ and $\mathrm{CL} / \mathrm{n}=5)$, low virulent strains $(3252 / \mathrm{n}=5$ and $\mathrm{AM} 64 / \mathrm{n}=5)$ and non-infected mice $(\mathrm{n}=10) 15$ days after infection. Tissue fragments of the heart were fixed in a $10 \%$ buffered formalin solution, dehydrated, cleared, and embedded in paraffin. Mononuclear inflammatory cells and amastigote nests were counted in thirty microscopic fields of $53,333.4 \mu \mathrm{m}^{2} /$ image, $4 \mu \mathrm{m}$-thick sections and stained with hematoxylin-eosin (HE) from each mouse, giving a total of $1.6 \times 10^{6} \mu \mathrm{m}^{2}$ of myocardium analyzed area. Images were obtained in an optical microscope (Olympus BX51), at a final magnification of $\times 400$ and analyzed using the ImageJ program.

\section{Real Time PCR}

Fragments of the heart tissue from mouse infected with each T. cruzi strain $(\mathrm{n}=10), 15$ days after inoculation, were collected, and total RNA was extracted using TRIzol reagent (Invitrogen ${ }^{\mathrm{TM}}$, Carlsbad, CA, USA) and SV Total RNA Isolation System kit (Promega, Madison, WT, USA). Purified RNA was stored at $-80^{\circ}$ C. RNA concentration and quality were analyzed using Nanodrop 2000 (Thermo Scientific, Waltham, MA, USA). cDNA was synthesized from $2 \mu \mathrm{g}$ of total RNA using the High Capacity cDNA Reverse Transcription kit (Applied Biosystems, USA).
The mRNA expression levels were detected by real-time PCR (qPCR) using Fast SYBR Green ${ }^{\circledR}$ Master Mix (Applied Biosystems, USA) according to the instructions of the manufacturer and specific primers (Table 1), which were obtained by the Primer Express software (Applied Biosystems, USA). Cycles of amplification were performed in a 7500 Fast Real-Time PCR System (Applied Biosystems) using 96 well plates (MicroAmp ${ }^{\circledR}$, Applied Biosystems, USA) and the standard PCR conditions consisted in an initial denaturation for $2 \mathrm{~min}$ at $50^{\circ} \mathrm{C}$ and at $95^{\circ} \mathrm{C}$ for $10 \mathrm{~min}$ followed by 40 cycles at $94^{\circ} \mathrm{C}$ for $30 \mathrm{~s}$, variable annealing primer temperature (Table 1) for $30 \mathrm{~s}$, and $72^{\circ}$ $\mathrm{C}$ for $1 \mathrm{~min}$. The determination of mRNA expression levels of innate immune receptors (TLR1, TLR2, TLR3, TLR4, TLR5, TLR6, TLR7, TLR8, TLR9, NOD1, NOD2, and NLRP3), signaling molecules (Myd88, TRIF, RIP2, ASC, and Caspase-1), cytokines (IL-1 $\beta$, IL-6, IL-10, IL-12p35, IL-12p40, IL-18, IFN- $\gamma$, and TNF- $\alpha$ ) and iNOS was carried out from the normalization of the result compared to the expression of the constitutive gene glyceraldehyde 3-phosphate dehydrogenase (GAPDH) using the $2^{-\Delta \Delta \mathrm{Ct}}$ formula.

\section{Cytokine Quantification}

Cytokine production was assayed in mice sera infected with high virulent strains (Colombian $/ \mathrm{n}=5$ and $\mathrm{Y} / \mathrm{n}=5$ ), medium virulent strains (PL $1.10 .14 / \mathrm{n}=5$ and $\mathrm{CL} / \mathrm{n}=5)$, low virulent strains $(3252 / \mathrm{n}=5$ and AM64/n = 5) 15 days after infection and a noninfected control group $(\mathrm{n}=10)$. The ELISA sets were IL-1 $\beta$, IL-12 (p70), IFN- $\gamma$, and TNF- $\alpha$ (BD OpTEIA, BD Bioscience, San Diego, CA), and procedures were performed according to the instructions of the manufacturer. Briefly, microwells were coated with $100 \mu \mathrm{l}$ of Capture Antibody (anti-IL-1 $\beta$, anti-IL-12, antiIFN- $\gamma$, and anti-TNF- $\alpha$ ) and incubated overnight at $4^{\circ} \mathrm{C}$. Plates were washed three times and blocked with assay diluent at room temperature for $1 \mathrm{~h}$. Microplates were washed three times and 100 $\mu \mathrm{l}$ of each standard, sample, and control were pipetted into appropriate wells, incubated for $2 \mathrm{~h}$ at room temperature. Three washes were performed, and $100 \mu \mathrm{l}$ detection antibody (anti-IL-1 $\beta /$ biotin, anti-IL-12/biotin, anti-IFN- $\gamma /$ biotin and antiTNF- $\alpha /$ biotin) together with avidin-HRP reagent was added to each well. Plates were incubated for $1 \mathrm{~h}$ at room temperature. Microplates were washed five times. Substrate solution $(100 \mu \mathrm{l} /$ TMB) was added to each well, and plate was incubated for $30 \mathrm{~min}$ at room temperature in the dark. Finally, added $50 \mu$ stop solution was added to each well. Optical densities were measured at $450 \eta \mathrm{m}$. Results were expressed as picograms per milliliter. The limits of sensitivity for IL-1 $\beta$, IL-12, IFN- $\gamma$, and TNF- $\alpha$ assays were $10 \mathrm{pg} / \mathrm{ml}$.

In order to express the repeatability and precision of the ELISA, the inter- and intra-assay Coefficients of Variation (CVs) were determined. Samples with known high and low concentrations of analyzed cytokines were used in all plates in duplicate. For the inter-assay $\mathrm{CV}$, the following formula was used: $\frac{[(\bar{X} h+S D h) \times 100]+[(\bar{X} 1+S D 1) \times 100]}{2}$, where $\bar{X} h$ and $\bar{X} l$ are the average of high and low control samples, respectively; $S D$ h and $S D \mathrm{l}$ are the standard deviation of high and low control samples, respectively. Inter-assay CVs ( $\mathrm{n}=4$ plates) were 5.7, 5.3, 6.5 , and $6.1 \%$ to IL- $1 \beta$, IL- 12 , IFN- $\gamma$, and TNF- $\alpha$, respectively. 
TABLE 1 | Sequence of the used specific starters in the reactions of PCR in real time.

\begin{tabular}{|c|c|c|}
\hline Iniciadores & Sense & Antisense \\
\hline GAPDH & TGCAGTGGCAAAGTGGAGAT & CGTGAGTGGAGTCATACTGGAA \\
\hline TLR1 & TCTCTTCGGCACGTTAGC & CGTAAGAAATAAGAGCAGCCC \\
\hline TLR2 & CGAGTGGTGCAAGTACG & GGTAGGTCTTGGTGTTCATTATC \\
\hline TLR3 & GGTGGTCCCGTTAATTCCT & CCCGAAAACATCCTTCTCAA \\
\hline TLR4 & ССТСTGССТTCACTACAGAGACTाT & TGTGGAAGCCTTCCTGGATG \\
\hline TLR5 & CGCACGGCTITATCTTCTCC & GGCAAGGTTCAGCATCTTCAA \\
\hline TLR6 & CCGGTGGAGTACCTCAAT & TCAGCAAACACCGAGTATAGC \\
\hline TLR7 & TGGAAATITTGGACCTCAGC & TTGCAAAGAAAGCGATTGTG \\
\hline TLR8 & CACGTGTGACATAAGTGATITCG & TाTGATCCCCAGGATTGGAA \\
\hline TLR9 & CTGCCGCTGACTAATCTG & CTGAAATTGTGGCCTATACCC \\
\hline NOD1 & GGACAACTTGCTGGAGAAT & CTGCAGCACGTAGAGGAA \\
\hline NOD2 & CTTCATTGGCTCATCCGTAG & CTGGAGATGTTGCAGTACAAAG \\
\hline NALP3 & AGCCTTCCAGGATCCTCTTC & GGGCAGCAGTTCTITC \\
\hline TRIF & ATTCAGGTGCCCGGGCGTG & TाTGCCGCTCTGCCTCCAGC \\
\hline MyD88 & TGATGCGGAGCCAGATT & GAGGAGGCATGTGTGTACT \\
\hline RIP2 & GGAGGAACAATCATCTATATGCC & ATGATCTGCAAAGGATTGGT \\
\hline ASC & AAGCTGCTGACAGTGCAAC & GCCACAGCTCCAGACTCTTC \\
\hline Caspase-1 & AGATGGCACATITCCAGGAC & ССTCCAGCAGCAACTTC \\
\hline$\| \mathrm{L}-1 \beta$ & GCAACTGTTCCTGAACTCAACT & ATCTITGGGGTCCGTCAACT \\
\hline IL-6 & CCATCCAGTTGCCTTCTTG & AAGTGCATCATCGTTGTTCATAC \\
\hline IL-10 & TGGACAACATACTGCTAACC & GGATCATITCCGATAAGGCT \\
\hline IL-12p35 & TCTCTGGACCTGCCAGGTGT & CCTGTTGATGGTCACGACGCG \\
\hline IL-12p40 & CAACATCAAGAGCAGTAGCAG & TACTCCCAGCTGACCTCCAC \\
\hline IL-18 & GTGAAGTAAGAGGACTGGCTGTG & TाTGGCAAGCAAGAAAGTGT \\
\hline TNF- $\alpha$ & TGTGCTCAGAGCTITCAACAA & CTTGATGGTGGTGCATGAGA \\
\hline IFN- $\gamma$ & GCATCTTGGCTाTGCAGCT & CCTITCGCCTTGCTGTTG \\
\hline iNOS & CGAAACGCTTCACTTCCAA & TGAGCCTATATTGCTGTGGCT \\
\hline
\end{tabular}

Intra-assay $\mathrm{CV}$ is the average of \% $\mathrm{CV}$ from all samples, being \% $C V=(\bar{X}+S D) \times 100$. Intra-assay CVs $(\mathrm{n}=140$ samples $)$ were 3.9 , $4.2,4.7$, and $5.1 \%$ to IL- $1 \beta$, IL- 12 , IFN- $\gamma$, and TNF- $\alpha$, respectively.

\section{Statistical Analysis}

The D'Agostino-Pearson and Kolmogorov-Smirnov tests were used to verify the distribution of the data. Data are presented as the mean \pm standard deviation (SD). Measurements of mRNA expression levels between all the groups were compared using Kruskal-Wallis test. Cytokines and myocarditis were compared between groups using ANOVA multiple comparisons test. Correlations were performed using the Spearman test. Differences were considered significant as follows: $\mathrm{p}<0.05\left(^{\star}\right)$, $\left.\mathrm{p}<0.01{ }^{* *}\right)$ and $\mathrm{p}<0,001\left(^{* * *}\right)$. The analyses were accomplished using PRISM 9.0 software (GraphPad, CA, USA).

\section{RESULTS}

\section{Virulence of T. cruzi Strains in Mice}

Initially, mice were infected with Colombian (Tc-I), Y (Tc-II), PL1.10.14 (Tc-III), AM64 (Tc-IV), 3253 (TC-V), and CL (Tc-VI) strains, and parasitemia and mortality were evaluated. Mice infected with Colombian and Y strains showed high levels of parasitemia and $100 \%$ mortality. Animals infected with PL1.10.14 and CL strains showed intermediate levels of parasitemia and 40\% mortality. On the other hand, AM64 and 3253 generate low parasitemia and $100 \%$ of survival in infected mice (Supplementary Figures S1A, B). Thus, T. cruzi strains were grouped into high virulent (Colombian and Y), medium virulent (PL1.10.14 and CL), and low virulent strains. Mice infected with high virulent strains showed high levels of parasitemia and $100 \%$ mortality, while the animals infected with medium virulent strains showed intermediate levels of parasitemia and 40\% mortality, and low virulent strains (AM64 and 3253) generate low parasitism load and $100 \%$ survival in mice (Figures 1A, B). After that we analyzed heart inflammation of mice according to its virulence and pathogenicity profile. As expected, hearts of uninfected mice showed no inflammation and hyaline degeneration (Figures 2A, E). Heart of mice infected with low virulent strains showed discrete myocarditis $\left(95 \pm 34\right.$ inflammatory cells/53,333.34 $\mu^{2}$ ) without or with low presence of amastigotes nests $(0.3 \pm 0.7$ amastigote nests/1.6 $\times 10^{6} \mu \mathrm{m}^{2}$ ), and few cardiac fibers had hyaline degeneration (Figures 2B, E, F). The infection with medium virulent strains generated moderate myocarditis $\left(197 \pm 43\right.$ inflammatory cells $\left./ 53,333.34 \mu^{2}\right)$, and amastigotes forms of parasite $\left(2.4 \pm 1.5\right.$ amastigote nests $\left./ 1.6 \times 10^{6} \mu \mathrm{m}^{2}\right)$ were visualized in histopathological analysis (Figures 2C, E, F). Interestingly, mice infected with high virulent strains showed intense inflammatory foci (327 \pm 68 inflammatory cells/ $53,333.34 \mu^{2}$ ) in myocardium with presence of several amastigote forms of parasite $(8.0 \pm 2.4$ amastigote nests $/ 1.6 \times$ $10^{6} \mu \mathrm{m}^{2}$ ), and large amounts of cardiac fibers are in hyaline degeneration (Figures 2D-F). The results showed that myocarditis increased according to strain virulence. 

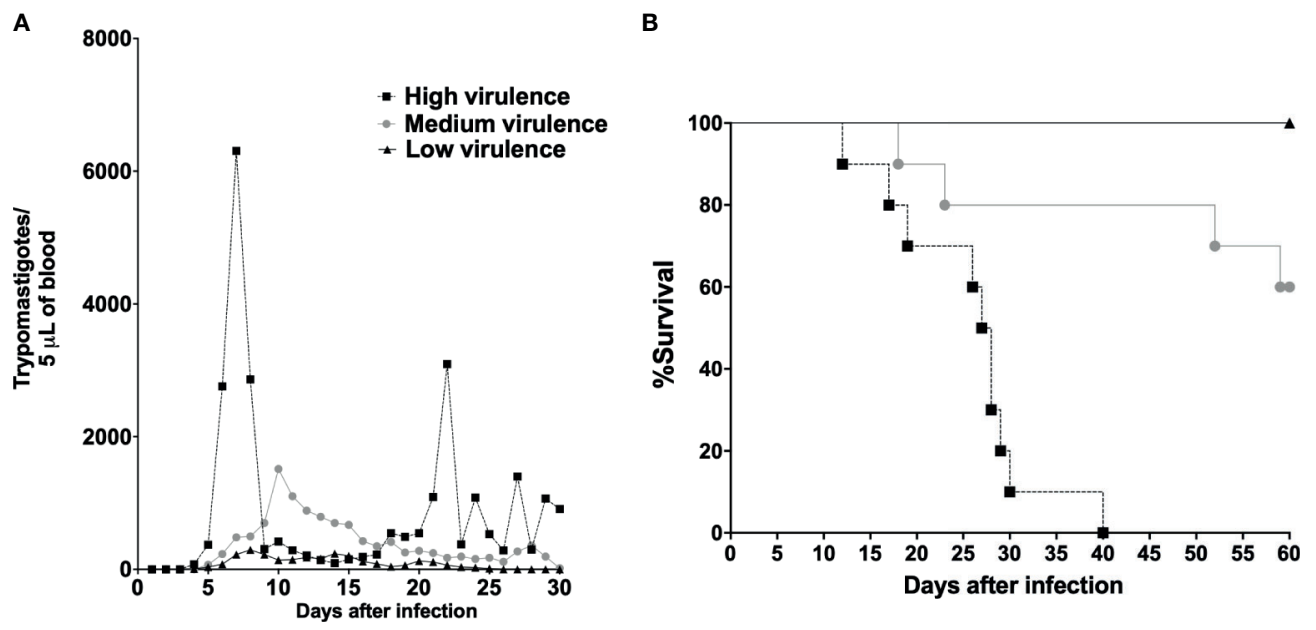

FIGURE 1 | Trypanosoma cruzi were grouped in high, medium, and low virulent strains according to parasitemia and survival in mice. Parasitemia (A) and survival (B) in Swiss mice infected by the intraperitoneal route with $1 \times 10^{4}$ blood trypomastigote forms of T. cruzi strains that showed high (Colombian $+\mathrm{Y}$ ), medium (PL1.10.14/Tclll + $\mathrm{CL} / \mathrm{TCVI})$, and low (AM64/TcIV $+3253 / \mathrm{TCV}$ virulence. The data are representative of two independent experiments $(\mathrm{n}=10$, ten animals were infected with each strain).

\section{Virulence of Trypanosoma cruzi Strains Is Related to Low Cardiac Expression of Important TLRs Involved in the Parasitism Control}

In an attempt to elucidate if the differential expression of TLRs and NLRs is involved in the pathogenicity induced by different strains of the parasite, we evaluated the TLR and NLR mRNA expression in heart tissue from mice infected with high, medium, and low virulent strains of T. cruzi. We did not observe a difference among TLR1, TLR3, TLR6, TLR7, and TLR8 mRNA expression in heart tissue of infected mice independently of the strain evaluated (Figures 3A, C, F, G, H). Interestingly, high virulent strains inhibited TLR2, TLR4, TLR5, and TLR9 mRNA expression in myocardium of infected mice, important molecules to T. cruzi infection resistance, when compared to medium and low virulent strains (Figures 3B, D, E, I). The next step was to evaluate the mRNA expression for downstream adapter molecules and cytokines in the heart tissue. High virulent strains inhibited TRIF, Myd88, IL-6, IL10, and IL-12 mRNA expression in myocardium of infected mice when compared to medium and low virulent strains (Figures 4A-F). Animals infected with high virulent strains showed mRNA expression of TRIF, Myd88, IL-6, IL10, and IL-12 similar to uninfected mice. We did not observe a significant difference between IFN- $\gamma$ transcripts in the heart from mice infected with strains that showed different profiles of virulence and pathogenicity (Figure 4G).

\section{High Virulence of Trypanosoma cruzi Strains Is Related to Exacerbated Expression of NLRP3, Caspase-1, IL-1 $\beta$, TNF- $\alpha$, and iNOS in the Myocardium}

Because high virulent strains induced an exacerbated inflammation in the myocardium of infected mice although they do not overexpress TLR-involved molecules or key inflammatory cytokines, we decided to analyze inflammasome- related gene expression. Interestingly, we observed an increase of NLRP3, caspase-1, IL-1 $\beta$, TNF- $\alpha$, and iNOS mRNA expression in the myocardium of mice infected with high virulent strain compared with animals infected with medium and low virulent strains (Figures 5A, C, G, H, J) We observed a similar and increased mRNA expression of ASC, NOD2, RIP2, and IL-18 in the heart of mice infected with high, medium, and low virulent strains compared to control group (Figures 5B, E, F, I). On the other hand, T. cruzi-infected mice showed a reduction of NOD1 mRNA expression in the heart when compared to uninfected animals, independent of parasite virulence (Figure 5D). In addition, correlation analyses showed a negative correlation between cardiac parasitism and TLR2, TLR4, TLR5, TLR7, TLR9, TRIF, IL-6, IL-10, IL-12p35, IL-12p40, and IFN- $\gamma$ mRNA expression (Figures 6A-K and Supplementary Table). Furthermore, we observed a positive correlation between cardiac parasitism and IL-1 $\beta$, TNF- $\alpha$, and iNOS mRNA expression (Figures 6L-N and Supplementary Table). We also observed a negative correlation between TLR4, TLR5, TRIF, IL-6, IL-10, and IL-12p35 mRNA expression and parasitemia peak levels in infected mice (Figures 7A-F and Supplementary Table). A positive correlation was observed between IL- $1 \beta$, TNF- $\alpha$, and iNOS mRNA expression and the number of blood trypomastigote forms (Figures 7G-I and Supplementary Table). Altogether, these data show that during experimental T. cruzi infection, cardiac parasitism is inversely correlated with the expression of important TLRs to parasite control. Moreover, high virulent T. cruzi strains induce an overexpression of NLRP3, caspase-1, IL-1 $\beta$, TNF- $\alpha$, and iNOS in the myocardium.

\section{Increased Production of IL-1 $\beta$ and TNF- $\alpha$ During the Acute Phase Is Correlated With High Virulence of the $T$. cruzi Strains}

In an attempt to validate results of RNA expression performed by PCR, we quantified the production of cytokines in the serum of 
Not infected

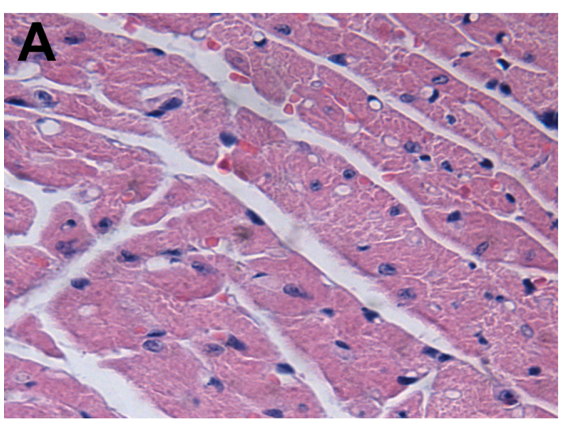

Medium virulence
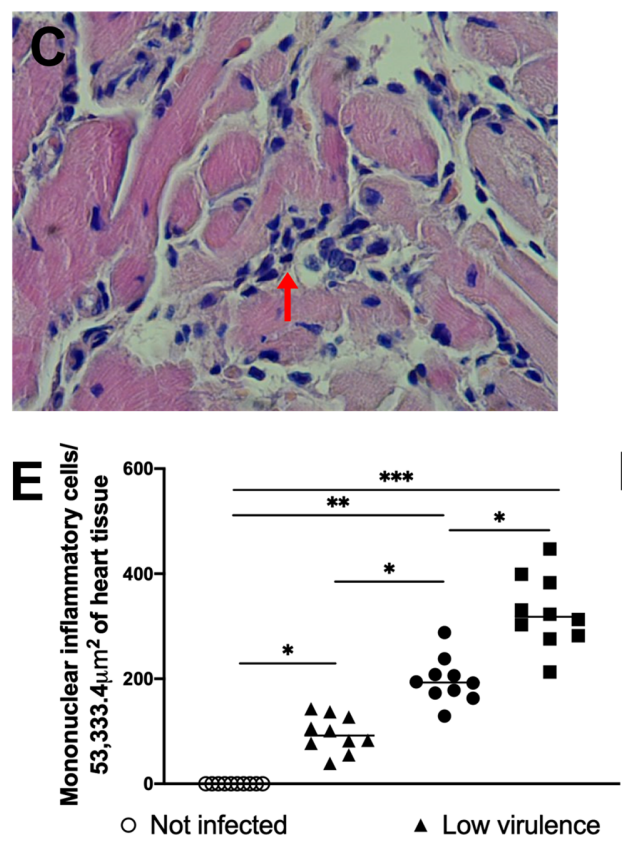

Low virulence

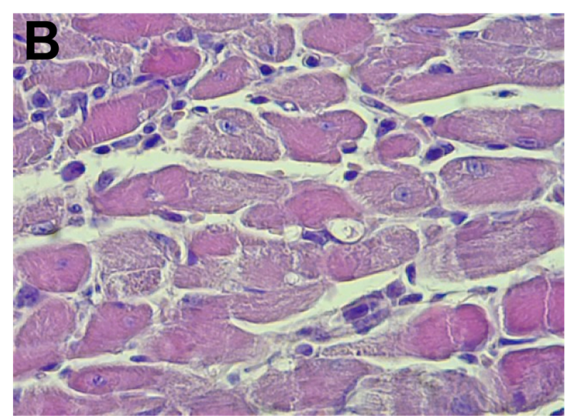

High virulence

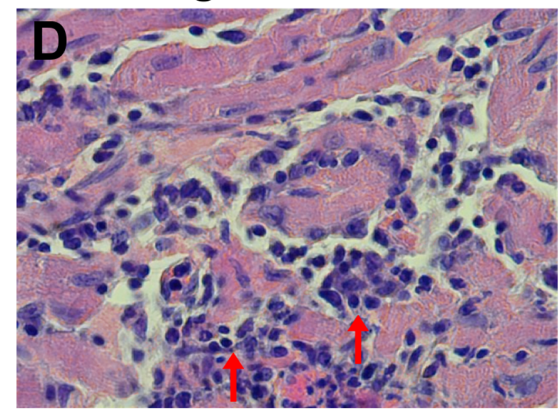

$\mathbf{F}$

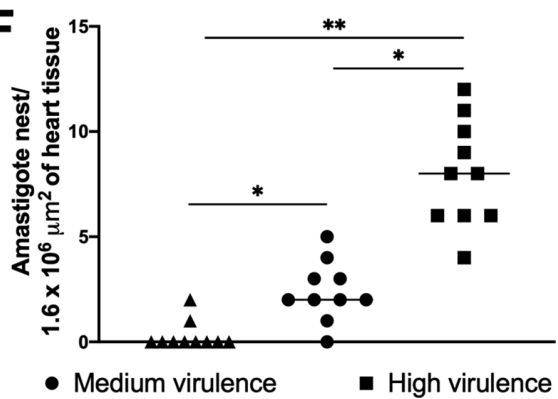

FIGURE 2 | Intensity of myocarditis in the acute phase in mice is related to Trypanosoma cruzi strain virulence. Representative histological sections of cardiac tissue from Swiss mice, not infected (A) and infected by the intraperitoneal route with $1 \times 10^{4}$ blood trypomastigote forms of T. cruzi strains that showed low (strains: AM64 + 3253) $(n=10)(\mathbf{B})$, medium (PL1.10.14 + CL) $(n=10)(\mathbf{C})$ and high (Colombian $+Y)(n=10)(\mathbf{D})$ virulence and euthanized 15 days after infection. Quantification of inflammatory mononuclear cells (E) and amastigote nests (F) in the heart tissue of mice. Hematoxylin and eosin staining was used. $\times 400$ magnification. Arrow indicates parasites. The results are expressed as the means \pm standard errors. ${ }^{*} p<0.05 ;{ }^{* *} p<0.01 ;{ }^{* \star *} p<0.001$.

mice infected with strains of the parasite that show different degrees of virulence. T. cruzi infection induced the production of significant levels of IL- $1 \beta$, TNF- $\alpha$, IL-12, and IFN- $\gamma$ in the serum of infected animals when compared to uninfected mice (Figures 8A-D). Interestingly, greater production of IL-1 $\beta$ was observed in the serum of mice infected with high virulence strains when compared to mice infected with medium and low virulence strains (Figure 8A). Furthermore, medium virulent strains induced greater production of IL-1 $\beta$ than strains of low virulence (Figure 8A). Thus, the production of IL- $1 \beta$ is modulated according to the virulence of the parasite strain. High and medium virulent strains also induced high TNF- $\alpha$ production in sera when compared to low virulent strains (Figure 8B). On the other hand, mice infected with medium virulence strains showed higher levels of IL-12, IFN- $\gamma$ in the serum, when compared to animals infected with low and high virulent strains (Figures 8C, D). These data suggest that virulence of T. cruzi strains during the acute phase of infection in mice is related with the overexpression of inflammasomerelated molecules and high levels of IL- $1 \beta$ and systemic TNF- $\alpha$.

\section{DISCUSSION}

It is already well known that T. cruzi parasite has populations with high genetic variability and diverse biological behavior causing different clinical courses in patients and experimental infections. Clinical outcomes can range from asymptomatic to 

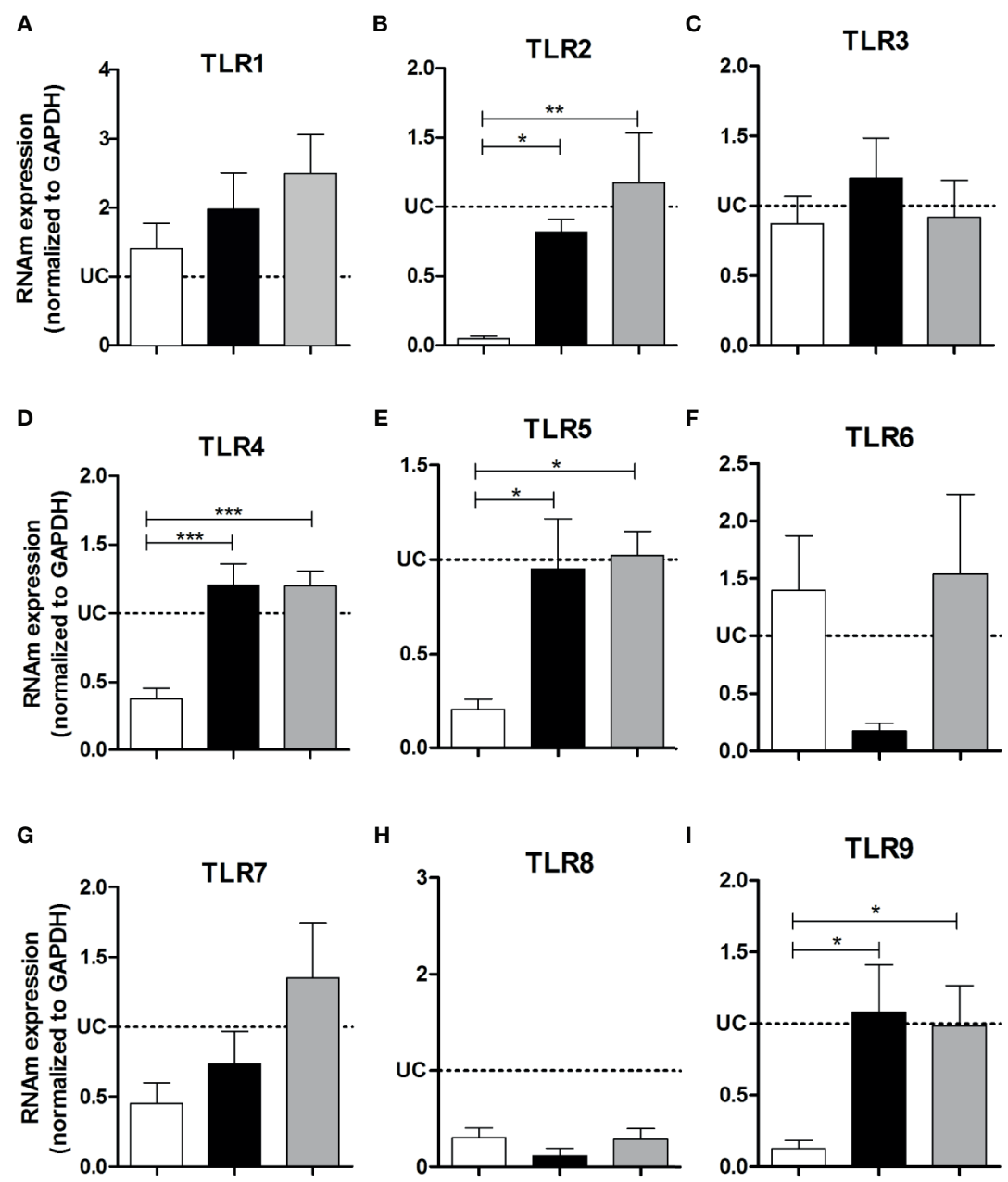

H
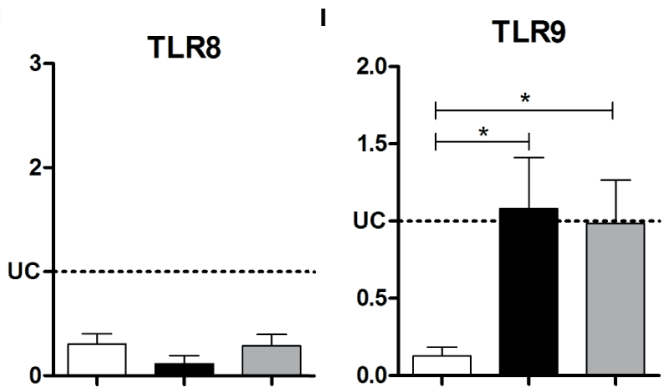

High virulence $\square$ Medium virulence $\square$ Low virulence

FIGURE 3 | Virulence of strains is correlated with TLR2, TLR4, TLR5, and TLR9 inhibition in heart from mice. The mRNA expression levels of TLR1 (A), TLR2 (B), TLR3 (C), TLR4 (D), TLR5 (E), TLR6 (F), TLR7 (G), TLR8 (H), and TLR9 (I) were determined by real-time PCR in heart of Swiss mice infected by the intraperitoneal route with $1 \times 10^{4}$ blood trypomastigote forms of $T$. cruzi strains that showed low (AM64 + 3253) $(n=10)$, medium (PL1.10.14 + CL) $(n=10)$ and high $(C o l o m b i a n+$ $Y)(n=10)$ virulence. The expression levels were normalized to the expression level of GAPDH. The results are expressed as the means \pm standard errors. ${ }^{*} p<0.05$; ${ }^{* \star} p<0.01 ;{ }^{* \star} p<0.001$. UC, uninfected control mice $(n=10)$.

100\% lethal (Chagas, 1909; Brener and Chiari, 1963; De Araujo and Chiari, 1988; Dias, 1989; Guedes et al., 2007; Zingales et al., 2009; Guedes et al., 2009). In the present study, T. cruzi strains were grouped according their virulence in the vertebrate host (mouse) and evaluated according the profile of innate immune receptors (TLRs and NLRs), adapter molecules, and cytokines induced.

We initially evaluated the parasitemia and survival of T. cruziinfected mice with the high (Colombian and Y), medium (CL strain and PL 1.10.14 isolate), and low virulent strains (AM64 strain and 3253 isolate). As expected, high virulent strains produced elevated parasitemia and myocarditis and generated $100 \%$ mortality in animals. Mortality of $100 \%$ in mice infected with Y and Colombian strains has already been described (De
Araujo and Chiari, 1988). CL strain and PL 1.10.14 isolate induced $40 \%$ mortality; literature data demonstrated $81 \%$ mortality in $\mathrm{C}_{3} \mathrm{H}$ mice infected with $10^{7}$ metacyclic trypomastigotes of CL strain (De Araujo and Chiari, 1988). Low virulent strains (AM64 strain and 3253 isolate) showed reduced parasitemia, low heart inflammation, and 100\% survival. Low levels of parasitemia and discreet myocarditis were previously described in Swiss mice infected with the same inoculum $\left(10^{4}\right.$ blood trypomastigotes) of AM-64 T. cruzi strain (Meza et al., 2014). However, data of parasitemia and survival in mice infected with PL 1.10.14 and 3253 are shown here for the first time.

Several studies have demonstrated the importance of TLR activation in the mechanism of protozoal infection control, such as T. cruzi, T. brucei, Leishmania spp., Plasmodium spp. and 
A

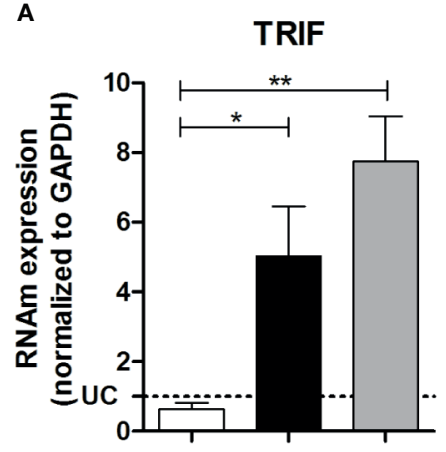

C

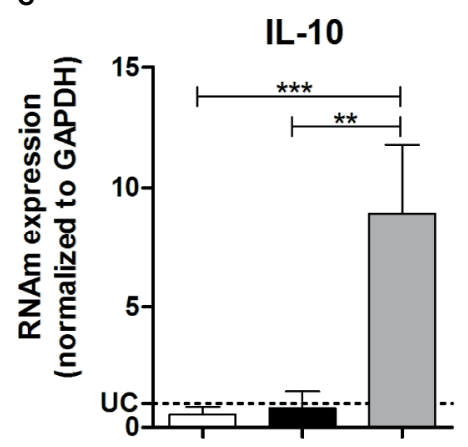

E

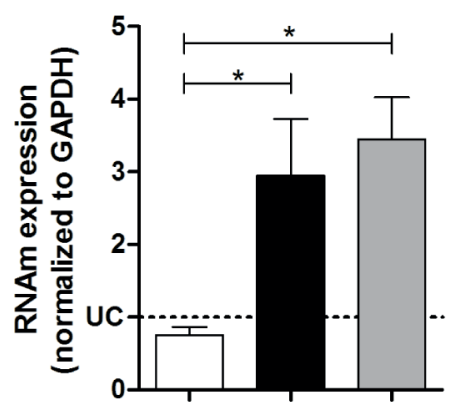

G

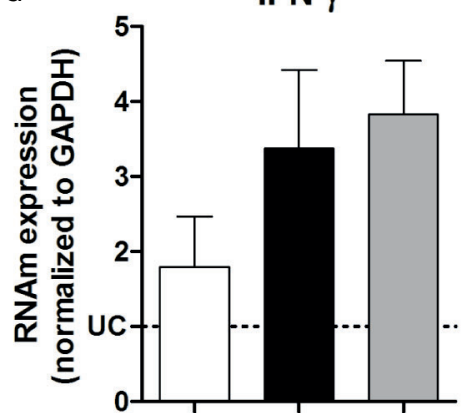

B

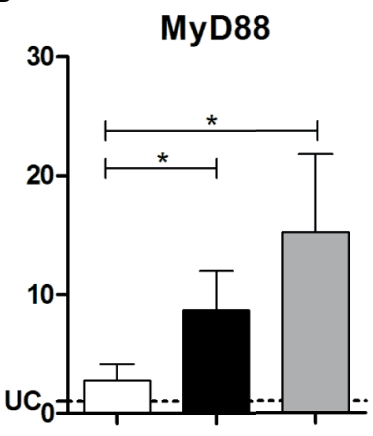

D

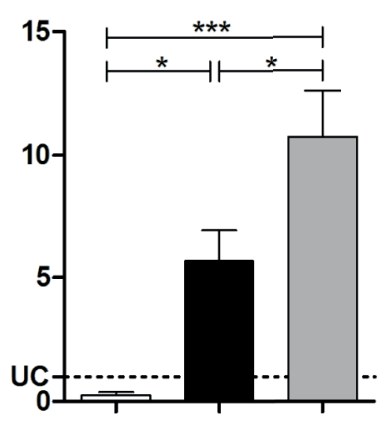

F IL-12p40

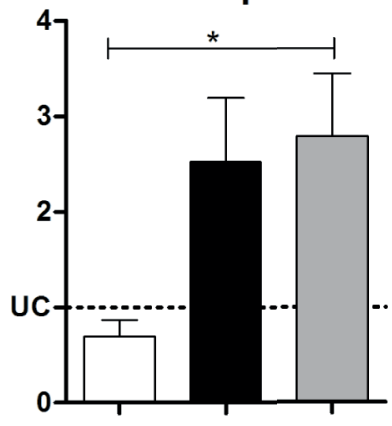

FIGURE 4 | Virulence of strains is correlated with TRIF, Myd88, IL-6, IL-12 inhibition in the heart from mice.The mRNA expression levels of TRIF (A), Myd88 (B), IL-10 (C), IL-6 (D), IL-12p35 (E), IL-12p40 (F), and IFN- $\gamma(\mathbf{G})$ were determined by real-time PCR in the heart from Swiss mice infected by the intraperitoneal route with $1 \times 10^{4}$ blood trypomastigote forms of T. cruzi strains that showed low (AM64 + 3253) $(n=10)$, medium (PL1.10.14 + CL) $(n=10)$, and high $(C o l o m b i a n+Y)$ $(n=10)$ virulence. The expression levels were normalized to the expression level of GAPDH. The results are expressed as the means \pm standard errors. ${ }^{*} p<0.05$; ${ }^{* *} p<0.01 ;{ }^{* \star *} p<0.001$. UC, uninfected control mice $(n=10)$. 
A

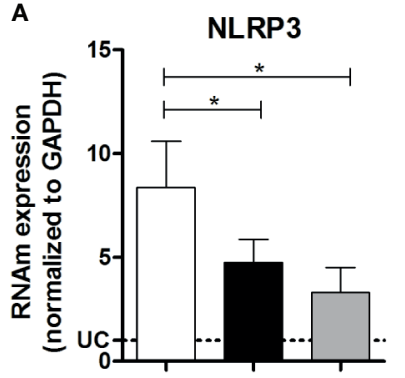

D

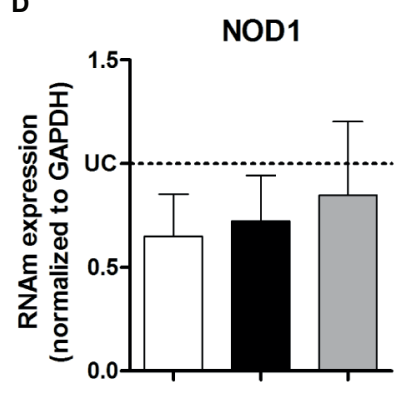

G
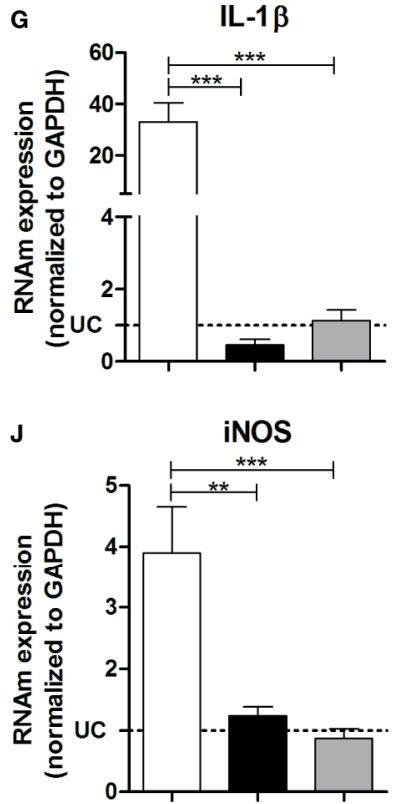

B

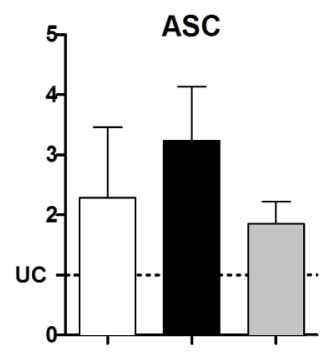

E
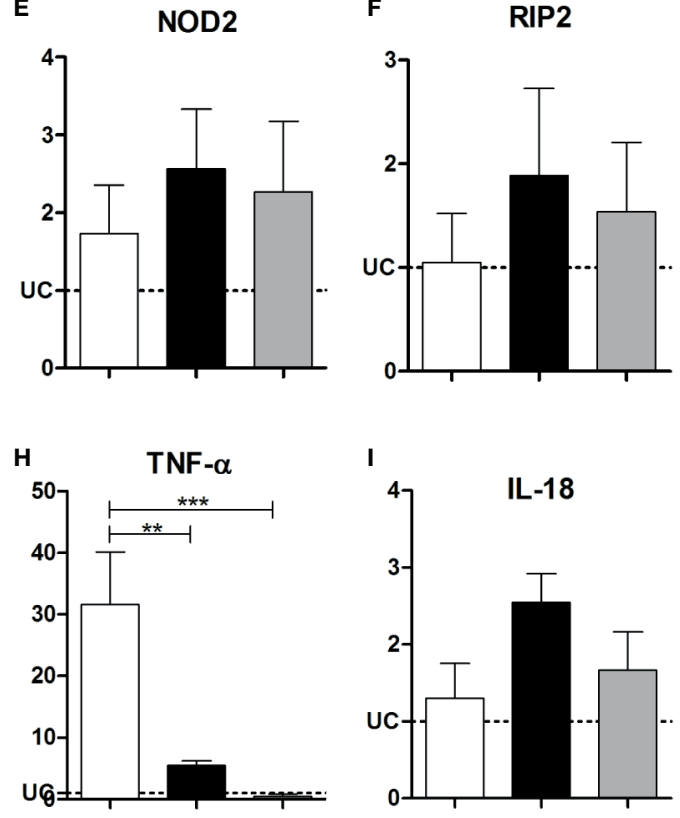

C
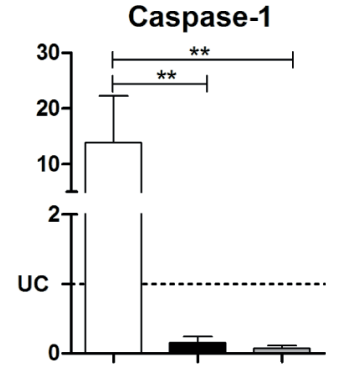

$\mathbf{F}$

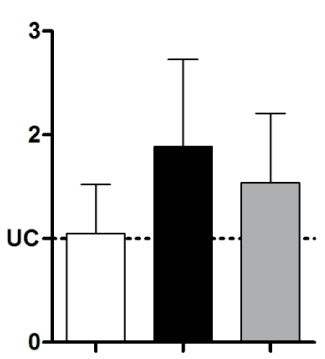

High virulence

Medium virulence

Low virulence

FIGURE 5 | Virulence of strains is correlated with NLRP-3, caspase-1, IL-1 $\beta$, TNF- $\alpha$, and iNOS increase in heart from mice. The mRNA expression levels of NLRP3 (A), ASC (B), caspase-1 (C), NOD1 (D), NOD2 (E), RIP2 (F), IL-1 $\beta$ (G), TNF- $\alpha(\mathbf{H})$, IL-18 (I), and iNOS (J) were determined by real-time PCR in the heart from Swiss mice infected by the intraperitoneal route with $1 \times 104$ blood trypomastigote forms of Trypanosoma cruzi strains that showed low (AM64 +3253$)(\mathrm{n}=10)$, medium $(P L 1.10 .14+C L)(n=10)$, and high (Colombian $+Y)(n=10)$ virulence. The expression levels were normalized to the expression level of GAPDH. The results are expressed as the means \pm standard errors. ${ }^{*} p<0.05 ;{ }^{* *} p<0.01 ;{ }^{* \star} p<0.001$. UC, uninfected control mice $(n=10)$.

Toxoplasma gondii in an experimental model (Gazzinelli and Denkers, 2006). Mice are the most used experimental models. Besides having TLR11, TLR12, TLR13 that humans do not express, they have nine conserved functional members of the toll-like family (TLRs 1-9) similar to humans. Also, TLR10 is selectively expressed in humans (Kawai and Akira, 2010).
However, correlation between TLR and NLR expression with virulence and pathogenicity profile generated after infection of the vertebrate host had not been evaluated yet. Interestingly, we observed that the animals infected with highly virulent strains showed inhibition in TLR2, TLR4, TLR5, and TLR9 mRNA expression in the heart. Several TLRs have been described as 
A

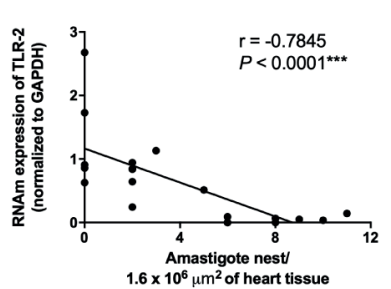

D
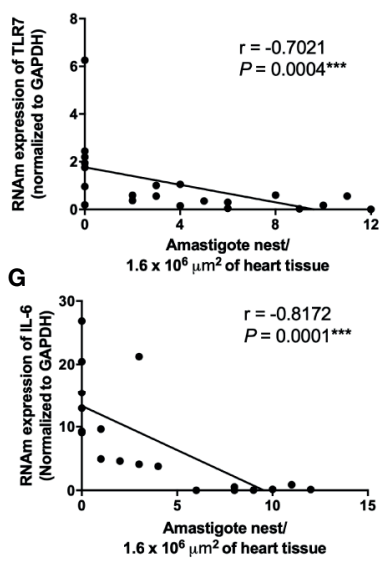

$\mathbf{J}$
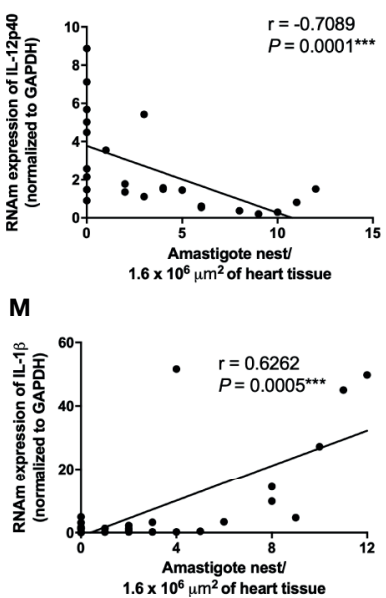

B

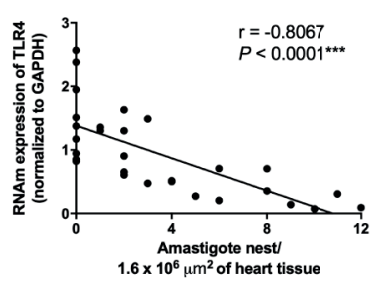

E
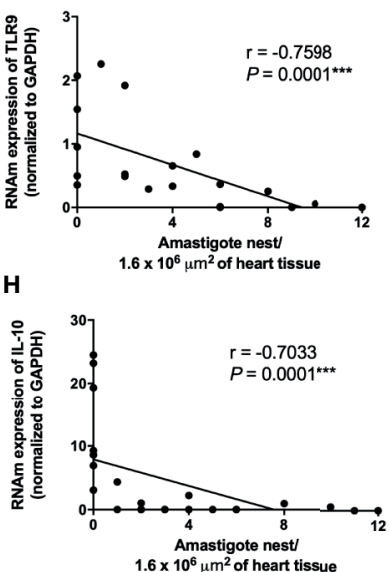

K

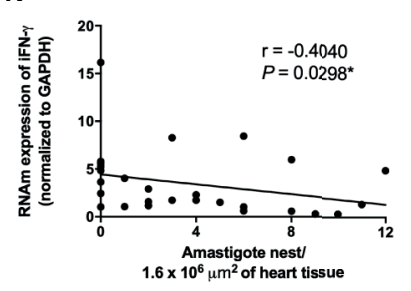

N

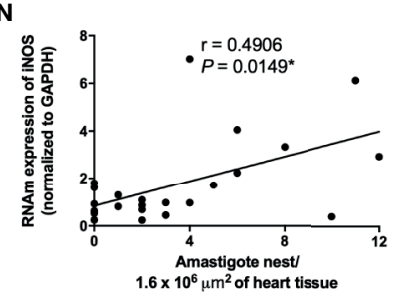

C

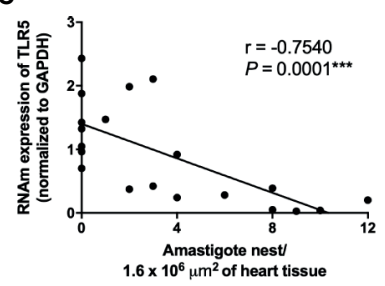

$\mathbf{F}$
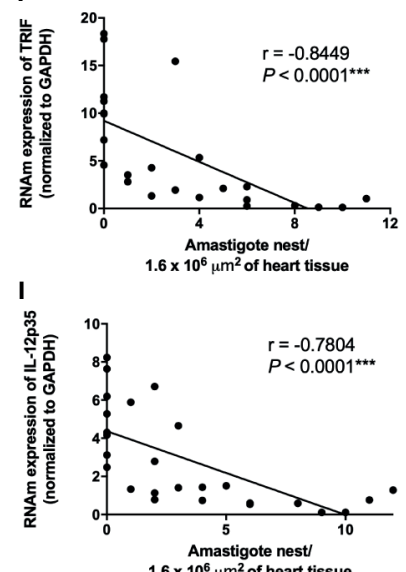

$\mathbf{L}$

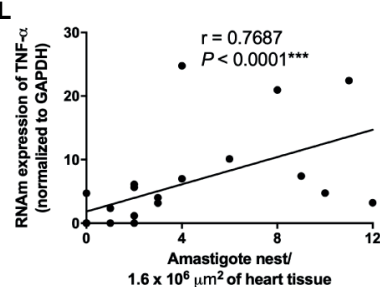

FIGURE 6 | Low TLR2, TLR4, TLR5, TLR7, TLR9, TRIF, IL-6, IL-10, IL-12p35, IL-12p40, IFN- $\gamma$ and high TNF- $\alpha$, IL-1 $\beta$, iNOS mRNA expression in cardiac tissue are correlated with high Trypanosoma cruzi virulence. The mRNA expression levels of TLR2 (A), TLR4 (B), TLR5 (C), TLR7 (D), TLR9 (E), TRIF (F), IL-6 (G), IL-10 (H), IL-12p35 (I), IL-12p40 (J), IFN- $\gamma$ (K), TNF- $\alpha$ (L), IL-1 $\beta$ (M), and iNOS (N) were determined by real-time PCR in cardiac tissue from Swiss mice infected by the intraperitoneal route with $1 \times 10^{4}$ blood trypomastigote forms of $T$. cruzi strains that showed low (AM64 + 3253) $(n=10)$, medium (PL1.10.14 + CL) $(n=10)$, and high $($ Colombian $+Y)(n=10)$ virulence. The expression levels were normalized to the expression level of GAPDH. The results are expressed as the means \pm standard errors and Spearman test was used. ${ }^{\star} p<0.05 ;{ }^{* \star *} p<0.001$.

important molecules in the resistance to T. cruzi experimental infection, such as TLR2 (Bafica et al., 2006), TLR4 (Oliveira et al., 2010), TLR7 (Caetano et al., 2011), and TLR9 (Bartholomeu et al., 2008). Mice deficient of these receptors are more susceptible to infection presenting higher parasitism and mortality. These molecules are activated by parasite PAMPs such as GPI anchors, GIPL, and nucleic acids (Campos et al., 2001; Koga et al., 2006; Oliveira et al., 2010; Caetano et al., 2011), stimulating downstream adapter molecules and inducing proinflammatory cytokine production. In addition, analysis of mRNA expression of adapter molecules involved in TLR signaling pathways demonstrated that infection with highly virulent T. cruzi strains induced inhibition in the expression of TRIF and MyD88 in the myocardium of infected animals. Animals deficient of TRIF and MyD88 infected with T. cruzi are more susceptible to infection, with higher parasitism and low 

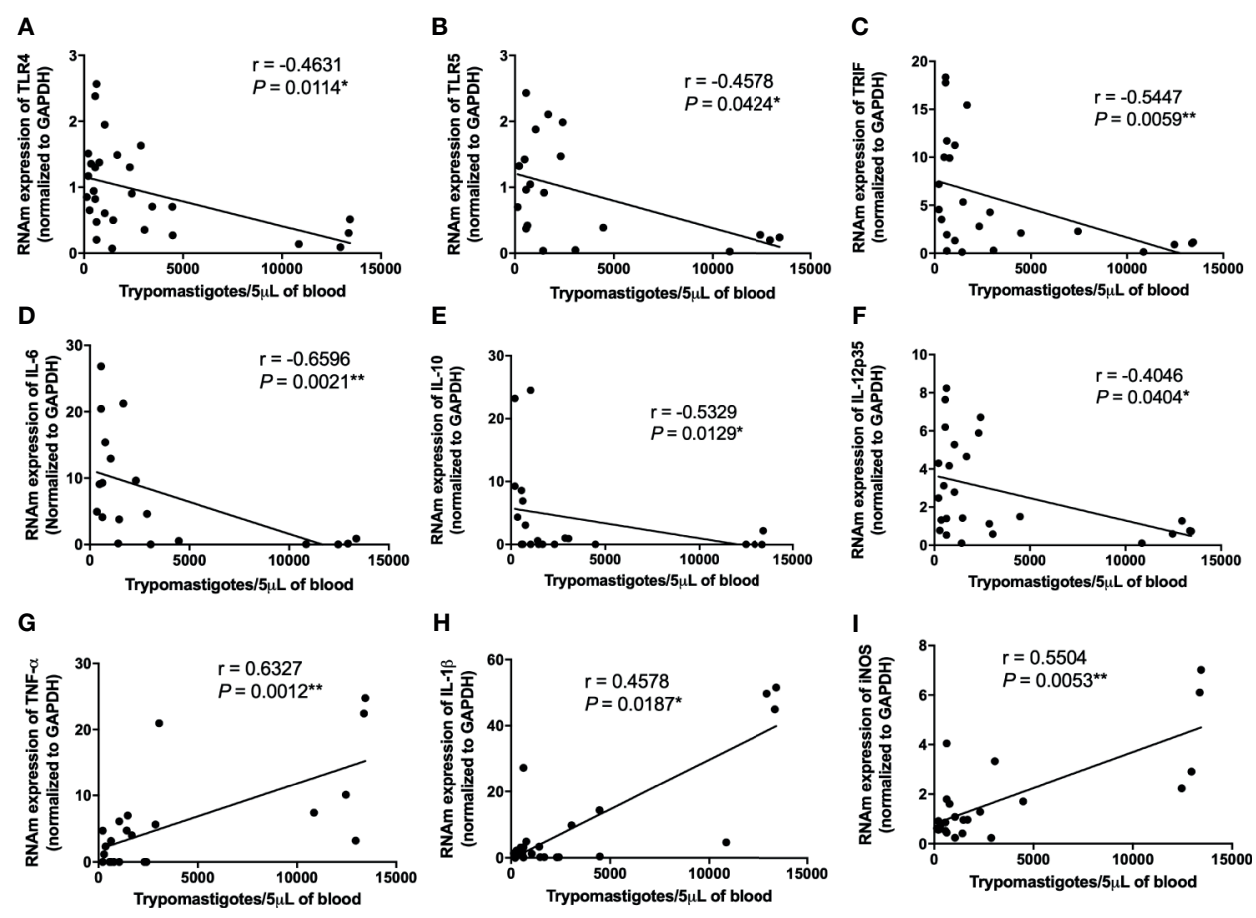

FIGURE 7 | Low TLR4, TLR5, TRIF, IL-6, IL-10, IL-12p35 and high TNF- $\alpha$, IL-1 $\beta$, iNOS mRNA expression in cardiac tissue are correlated with high Trypanosoma cruzi virulence. The mRNA expression levels of TLR4 (A), TLR5 (B), TRIF (C), IL-6 (D), IL-10 (E), IL-12p35 (F), TNF- $\alpha$ (G), IL-1 13 (H) and iNOS (I) were determined by real-time PCR in cardiac tissue from Swiss mice infected by the intraperitoneal route with $1 \times 10^{4}$ blood trypomastigote forms of $T$. cruzi strains that showed low $($ AM64 + 3253) $(n=10)$, medium (PL1.10.14 $+C L)(n=10)$, and high (Colombian $+Y)(n=10)$ virulence. The expression levels were normalized to the expression level of GAPDH. The results are expressed as the means \pm standard errors and Spearman test was used. ${ }^{*} p<0.05 ;{ }^{* \star *} p<0.001$.

macrophage activation, resulting in a low production of nitric oxide (Campos and Gazzinelli, 2004; Koga et al., 2006; Bafica et al., 2006; Oliveira et al., 2010). On the other hand, medium and low virulent strains showed greater expression of these innate immunity receptors involved in the host resistance to T. cruzi infection when compared to high virulent strains.

In this study, inflammasome pathway analysis showed that infection with virulent strains of T. cruzi leads to high increase in the expression of NLRP3, caspase- 1 and IL-1 $\beta$ in the myocardium. The high expression of these molecules may be related to the induction of inflammatory cytokines and the consequent production of nitric oxide, causing an intense inflammatory process, tissue damages, and early mortality in mice. In contrast, animals infected with strains that show low virulence showed slight enhancement of NLRP3, caspase-1, IL$1 \beta$ and discreet myocarditis. Previous studies have shown that NLRP3 and caspase-1 deficient mice, experimentally infected with T. cruzi Y strain, have deficit NO production, which is crucial for parasite clearance, while the excess production of these molecules can generate deleterious effects on the host (Goncalves et al., 2013; Silva et al., 2013).

In this study, animals infected with highly virulent and pathogenic strains (Colombian and Y) presented a high mRNA expression of IL- $1 \beta$ and TNF- $\alpha$ in the myocardium and high serum concentrations of these cytokines. This exacerbated profile of proinflammatory cytokines is associated with high production of NO, which helps in parasitism control and can cause intense tissue destruction contributing to animal mortality. High TNF- $\alpha$ production may exhibit protective roles, activating macrophages but causing tissue damage generating deleterious effects on the host (Truyens et al., 1999; Holscher et al., 2000; Malvezi et al., 2004). The high expression of IL-1 $\beta$ is observed in patients with cardiac form of Chagas disease, and its action is correlated to cardiac hypertrophy and inhibition of fibroblast proliferation, indicating the IL-1 $\beta$ role in cardiac remodeling (Patten et al., 1996; Lachtermacher et al., 2010; Sousa et al., 2014). On the other hand, IL- $1 \beta$ showed antiparasitary action leading to TNF- $\alpha$ and NO production in the culture of murine cardiomyocytes infected by T. cruzi (Postan et al., 1999). The high production of NO by the enzyme iNOS has been associated with death of murine cardiomyocytes by triggering a programmed cell death process (Pinsky et al., 1999). Furthermore, culture of murine macrophages and cardiomyocytes with combinations of IL-1 $\beta$, TNF- $\alpha$, and IFN- $\gamma$ results in death of these cells, and the lethal effects are blocked by using iNOS inhibitors or adding TGF- $\beta$ (Pinsky et al., 1999).

Our data also showed that the infection with high virulent and pathogenic strains led to reduced expression of IL- 6 and IL12. These cytokines play an important role in the control of parasite replication; IL-6 deficient animals show higher parasitemia and early mortality (Muller et al., 2001; Gao and Pereira, 2002). These results suggest that deficient expression 

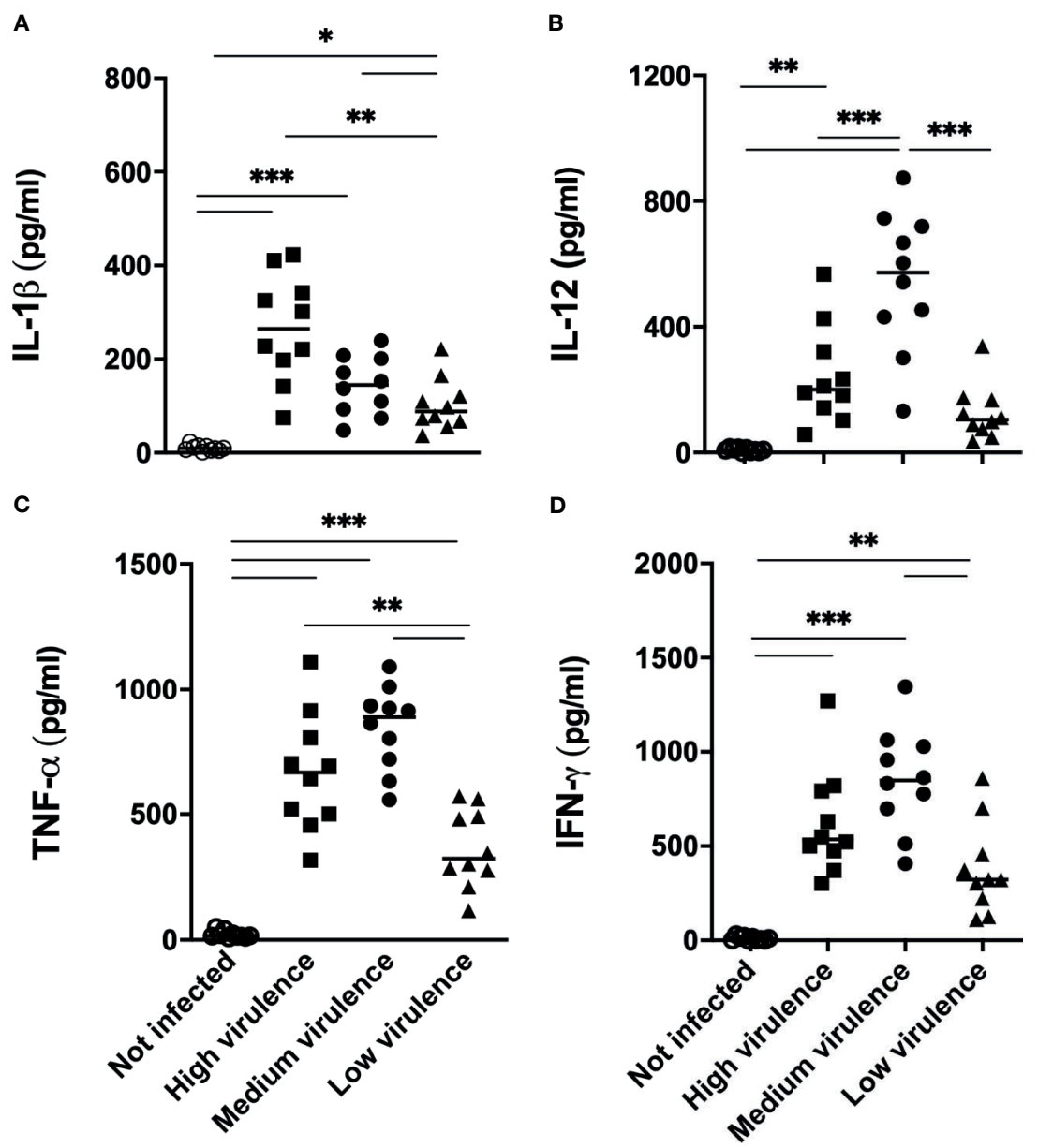

FIGURE 8 | IL-1 $\beta$ and TNF- $\alpha$ in sera from mice infected with Trypanosoma cruzi are correlated with strain virulence (parasitemia, survival, and myocarditis). IL-1 $\beta$ (A), TNF- $\alpha$ (B), IL-12 (C) and IFN- $\gamma$ (D) were quantified in the sera (15 days after infection) by ELISA from Swiss mice infected by the intraperitoneal route with $1 \times$ $10^{4}$ blood trypomastigote forms of $T$. cruzi strains that showed low (AM64 +3253) $(n=10)$, medium (PL1.10.14 $\left.+C L\right)(n=10)$, and high $(C o l o m b i a n+Y)(n=10)$ virulence. The results are expressed as the means \pm standard errors. ${ }^{*} p<0.05 ;{ }^{* \star} p<0.01 ;{ }^{* \star *} p<0.001$. UC, uninfected control mice $(n=10)$.

of TLR2, TLR4, TLR9 may impact on the reduced production of IL-6 and IL-12, exacerbating parasite replication and host death. In addition, a negative correlation was observed between mRNA expression of TLR4, TLR5, IL-6, and parasitemia levels. On the other hand, strains with low virulence and pathogenicity induced high expression of important TLRs and cytokines in the control of $T$. cruzi infection. In addition to regulation (inhibition or stimulation) of TLRs and NLRs, qualitative and quantitative differences in cardiac inflammatory infiltrate differentially induced by strains with high, medium, and low virulence also influence the gene expression of molecules involved in the innate immune response in cardiac tissue.

Altogether, our findings suggest that virulence of T. cruzi strains is related to the inhibition of innate immune receptors, adapter molecules, and cytokines important to parasitism control (TLR4, TLR9, TRIF, Myd88, IL-6, and IL-12) associated with increased expression of molecules that contribute to myocardial inflammation, damage, and mortality (NLRP3, caspase-1, IL-1 $\beta$ and TNF- $\alpha$ ). Future studies will be required to identify parasite molecules implicated in the activation of the TLR receptor signaling cascade and NLR receptor signaling pathway to understand the underlying mechanisms at the interface of the immune response of the host and virulence of $T$. cruzi and its association with the pathogenesis of Chagas disease.

\section{DATA AVAILABILITY STATEMENT}

The original contributions presented in the study are included in the article/Supplementary Material. Further inquiries can be directed to the corresponding author.

\section{ETHICS STATEMENT}

The animal study was reviewed and approved by Ethics Committee on Animal Use (CEUA) of the Federal University of Rio Grande do Norte (UFRN). 


\section{AUTHOR CONTRIBUTIONS}

TQ, MN, and PG wrote the manuscript. CA, RA-J, CB, LG, AC, MN, PG conceptualize the experiments. TQ, NP, DS, CB, RA-J, and PG performed the experiments and analyzed the data. LG, $\mathrm{AC}, \mathrm{MN}$, and $\mathrm{PG}$ were responsible for the funding acquisition. PG was the supervision of the research. All authors contributed to the article and approved the submitted version.

\section{FUNDING}

This work was supported by the Conselho Nacional de Desenvolvimento Científico e Tecnológico (CNPq/MS/SCTIE/ DECIT grant no. 466698/2014-3, MCT/CNPq) and financed in part by the Coordenação de Aperfeiçoamento de Pessoal de Nível

\section{REFERENCES}

Abrahamsohn, I. A., and Coffman, R. L. (1996). Trypanosoma Cruzi: IL-10, TNF, IFN-Gamma, and IL-12 Regulate Innate and Acquired Immunity to Infection. Exp. Parasitol 84 (2), 231-244. doi: 10.1006/expr.1996.0109

Aliberti, J. C., Cardoso, M. A., Martins, G. A., Gazzinelli, R. T., Vieira, L. Q., and Silva, J. S. (1996). Interleukin-12 Mediates Resistance to Trypanosoma Cruzi in Mice and Is Produced by Murine Macrophages in Response to Live Trypomastigotes. Infect Immun. 64 (6), 1961-1967. doi: 10.1128/iai.64.6. 1961-1967.1996

Bafica, A., Santiago, H. C., Goldszmid, R., Ropert, C., Gazzinelli, R. T., and Sher, A. (2006). Cutting Edge: TLR9 and TLR2 Signaling Together Account for MyD88-Dependent Control of Parasitemia in Trypanosoma Cruzi Infection. J. Immunol. 177 (6), 3515-3519. doi: 10.4049/jimmunol.177. 6.3515

Bahia-Oliveira, L. M., Gomes, J. A., Rocha, M. O., Moreira, M. C., Lemos, E. M., Luz, Z. M., et al. (1998). IFN-Gamma in Human Chagas' Disease: Protection or Pathology? Braz. J. Med. Biol. Res. = Rev. Bras. pesquisas Med e biologicas/ Sociedade Bras. Biofisica [et al.] 31 (1), 127-131. doi: 10.1590/s0100879x1998000100017

Bartholomeu, D. C., Ropert, C., Melo, M. B., Parroche, P., Junqueira, C. F., Teixeira, S. M., et al. (2008). Recruitment and Endo-Lysosomal Activation of TLR9 in Dendritic Cells Infected With Trypanosoma Cruzi. J. Immunol. 181 (2), 1333-1344. doi: 10.4049/jimmunol.181.2.1333

Brener, Z. (1962). Therapeutic Activity and Criterion of Cure on Mice Experimentally Infected With Trypanosoma Cruzi. Rev. do Instituto Medicina Trop. Sao Paulo 4, 389-396.

Brener, Z., and Chiari, E. (1963). Morphological Variations Observed in Different Strains of Trypanosoma Cruzi. Rev. do Instituto Medicina Trop. Sao Paulo 5, 220-224.

Caetano, B. C., Carmo, B. B., Melo, M. B., Cerny, A., dos Santos, S. L., Bartholomeu, D. C., et al. (2011). Requirement of UNC93B1 Reveals a Critical Role for TLR7 in Host Resistance to Primary Infection With Trypanosoma Cruzi. J. Immunol. 187 (4), 1903-1911. doi: 10.4049/jimmunol.1003911

Campos, M. A., Almeida, I. C., Takeuchi, O., Akira, S., Valente, E. P., Procopio, D. O., et al. (2001). Activation of Toll-Like Receptor-2 by Glycosylphosphatidylinositol Anchors From a Protozoan Parasite. J. Immunol. 167 (1), 416-423. doi: 10.4049/ jimmunol.167.1.416

Campos, M. A., and Gazzinelli, R. T. (2004). Trypanosoma Cruzi and Its Components as Exogenous Mediators of Inflammation Recognized Through Toll-Like Receptors. Mediators Inflammation 13 (3), 139-143. doi: 10.1080/ 09511920410001713565

Chagas, C. (1909). Nova Tripanossomíase Humana. Mem Inst Oswaldo Cruz 1, 159-218. doi: 10.1590/S0074-02761909000200008

De Araujo, S. M., and Chiari, E. (1988). Biological Characterization of Clones of the Y, CL and MR Strains of Trypanosoma Cruzi in Inbred C3H Mice. Mem Inst Oswaldo Cruz 83 (2), 175-181.
Superior - Brasil (CAPES) - Finance Code 001. The authors (PG and $\mathrm{MN}$ ) receives a scientific productivity scholarship from Conselho Nacional de Desenvolvimento Científico e Tecnológico (CNPq).

\section{SUPPLEMENTARY MATERIAL}

The Supplementary Material for this article can be found online at: https://www.frontiersin.org/articles/10.3389/fcimb.2021.696719/ full\#supplementary-material

Supplementary Figure 1 | Parasitemia (A) and survival (B) in Swiss mice infected by the intraperitoneal route with $1 \times 104$ blood trypomastigotes forms of Trypanosoma cruzi Colombian (Tcl), Y (Tcll), PL1.10.14 (TcIII), AM64 (TcIV), 3253 (TcV) and $\mathrm{CL}(\mathrm{TCV})$ strains. The data are representative of two independent experiments ( $n=10$, ten animals were infected with each strain).

Dias, J. C. (1989). The Indeterminate Form of Human Chronic Chagas' Disease A Clinical Epidemiological Review. Rev. da Sociedade Bras. Medicina Trop. 22 (3), 147-156. doi: 10.1590/S0037-86821989000300007

Dias, J. C., Machado, E. M., Fernandes, A. L., and Vinhaes, M. C. (2000). General Situation and Perspectives of Chagas Disease in Northeastern Region, Brazil. Cad Saude Publica 16 Suppl 2, 13-34. doi: 10.1590/S0102-311X2000000800003

Dutra, W. O., Martins-Filho, O. A., Cancado, J. R., Pinto-Dias, J. C., Brener, Z., Freeman Junior, G. L., et al. (1994). Activated T and B Lymphocytes in Peripheral Blood of Patients With Chagas' Disease. Int. Immunol. 6 (4), 499506. doi: 10.1093/intimm/6.4.499

Federici, E. E., Abelmann, W. H., and Neva, F. A. (1964). Chronic and Progressive Myocarditis and Myositis in C3h Mice Infected With Trypanosoma Cruzi. Am. J. Trop. Med. hygiene 13, 272-280. doi: 10.4269/ajtmh.1964.13.272

Gao, W., and Pereira, M. A. (2002). Interleukin-6 Is Required for Parasite Specific Response and Host Resistance to Trypanosoma Cruzi. Int. J. Parasitol 32 (2), 167-170. doi: 10.1016/S0020-7519(01)00322-8

Gazzinelli, R. T., and Denkers, E. Y. (2006). Protozoan Encounters With Toll-Like Receptor Signalling Pathways: Implications for Host Parasitism. Nat. Rev. Immunol. 6 (12), 895-906. doi: 10.1038/nri1978

Gomes, J. A., Bahia-Oliveira, L. M., Rocha, M. O., Martins-Filho, O. A., Gazzinelli, G., and Correa-Oliveira, R. (2003). Evidence That Development of Severe Cardiomyopathy in Human Chagas' Disease Is Due to a Th1-Specific Immune Response. Infect Immun. 71 (3), 1185-1193. doi: 10.1128/IAI.71.3.1185-1193.2003

Goncalves, V. M., Matteucci, K. C., Buzzo, C. L., Miollo, B. H., Ferrante, D., Torrecilhas, A. C., et al. (2013). NLRP3 Controls Trypanosoma Cruzi Infection Through a Caspase-1-Dependent IL-1R-Independent NO Production. PloS neglected Trop. Dis. 7 (10), e2469. doi: 10.1371/journal.pntd.0002469

Guedes, P. M., Veloso, V. M., Afonso, L. C., Caliari, M. V., Carneiro, C. M., Diniz, L. F., et al. (2009). Development of Chronic Cardiomyopathy in Canine Chagas Disease Correlates With High IFN-Gamma, TNF-Alpha, and Low IL-10 Production During the Acute Infection Phase. Veterinary Immunol. Immunopathol 130 (1-2), 43-52. doi: 10.1016/j.vetimm.2009.01.004

Guedes, P. M., Veloso, V. M., Caliari, M. V., Carneiro, C. M., Souza, S. M., de Lana, M., et al. (2007). Trypanosoma Cruzi High Infectivity In Vitro Is Related to Cardiac Lesions During Long-Term Infection in Beagle Dogs. Memorias do Instituto Oswaldo Cruz 102 (2), 141-147. doi: 10.1590/S0074-02762007 000200003

Gutierrez, F. R., Guedes, P. M., Gazzinelli, R. T., and Silva, J. S. (2009). The Role of Parasite Persistence in Pathogenesis of Chagas Heart Disease. Parasite Immunol. 31 (11), 673-685. doi: 10.1111/j.1365-3024.2009.01108.x

Holscher, C., Kohler, G., Muller, U., Mossmann, H., Schaub, G. A., and Brombacher, F. (1998). Defective Nitric Oxide Effector Functions Lead to Extreme Susceptibility of Trypanosoma Cruzi-Infected Mice Deficient in Gamma Interferon Receptor or Inducible Nitric Oxide Synthase. Infect Immun. 66 (3), 1208-1215. doi: 10.1128/IAI.66.3.1208-1215.1998

Holscher, C., Mohrs, M., Dai, W. J., Kohler, G., Ryffel, B., Schaub, G. A., et al. (2000). Tumor Necrosis Factor Alpha-Mediated Toxic Shock in Trypanosoma 
Cruzi-Infected Interleukin 10-Deficient Mice. Infect Immun. 68 (7), 40754083. doi: 10.1128/IAI.68.7.4075-4083.2000

Kawai, T., and Akira, S. (2010). The Role of Pattern-Recognition Receptors in Innate Immunity: Update on Toll-Like Receptors. Nat. Immunol. 11 (5), 373384. doi: $10.1038 /$ ni. 1863

Koga, R., Hamano, S., Kuwata, H., Atarashi, K., Ogawa, M., Hisaeda, H., et al. (2006). TLR-Dependent Induction of IFN-Beta Mediates Host Defense Against Trypanosoma Cruzi. J. Immunol. 177 (10), 7059-7066. doi: 10.4049/ jimmunol.177.10.7059

Lachtermacher, S., Esporcatte, B. L., Montalvao, F., Costa, P. C., Rodrigues, D. C., Belem, L., et al. (2010). Cardiac Gene Expression and Systemic Cytokine Profile Are Complementary in a Murine Model of Post-Ischemic Heart Failure. Braz. J. Med. Biol. Res. = Rev. Bras. pesquisas Med e biologicas/Sociedade Bras. Biofisica [et al] 43 (4), 377-389. doi: 10.1590/S0100-879X2010007500014

Malvezi, A. D., Cecchini, R., de Souza, F., Tadokoro, C. E., Rizzo, L. V., and PingeFilho, P. (2004). Involvement of Nitric Oxide (NO) and TNF-Alpha in the Oxidative Stress Associated With Anemia in Experimental Trypanosoma Cruzi Infection. FEMS Immunol. Med. Microbiol. 41 (1), 69-77. doi: 10.1016/ j.femsim.2004.01.005

Martins, K., Andrade Cde, M., Barbosa-Silva, A. N., do Nascimento, G. B., Chiari, E., Galvao, L. M., et al. (2015). Trypanosoma Cruzi III Causing the Indeterminate Form of Chagas Disease in a Semi-Arid Region of Brazil. Int. J. Infect. diseases: IJID: Off. Publ. Int. Soc. Infect. Dis. 39, 68-75. doi: 10.1016/ j.ijid.2015.08.012

Meza, S. K., Kaneshima, E. N., Silva Sde, O., Gabriel, M., de Araujo, S. M., Gomes, M. L., et al. (2014). Comparative Pathogenicity in Swiss Mice of Trypanosoma Cruzi IV From Northern Brazil and Trypanosoma Cruzi II From Southern Brazil. Exp. Parasitol 146, 34-42. doi: 10.1016/j.exppara.2014.08.014

Muller, U., Kohler, G., Mossmann, H., Schaub, G. A., Alber, G., Di Santo, J. P., et al. (2001). IL-12-Independent IFN-Gamma Production by T Cells in Experimental Chagas' Disease Is Mediated by IL-18. J. Immunol. 167 (6), 3346-3353. doi: 10.4049/jimmunol.167.6.3346

Oliveira, A. C., de Alencar, B. C., Tzelepis, F., Klezewsky, W., da Silva, R. N., Neves, F. S., et al. (2010). Impaired Innate Immunity in Tlr4(-/-) Mice But Preserved CD8+ T Cell Responses Against Trypanosoma Cruzi in Tlr4-, Tlr2-, Tlr9- or Myd88-Deficient Mice. PloS Pathog. 6 (4), e1000870. doi: 10.1371/ journal.ppat.1000870

Oliveira, A. C., Peixoto, J. R., de Arruda, L. B., Campos, M. A., Gazzinelli, R. T., Golenbock, D. T., et al. (2004). Expression of Functional TLR4 Confers Proinflammatory Responsiveness to Trypanosoma Cruzi Glycoinositolphospholipids and Higher Resistance to Infection With T. Cruzi. J. Immunol. 173 (9), 5688-5696. doi: 10.4049/jimmunol.173.9.5688

Patten, M., Hartogensis, W. E., and Long, C. S. (1996). Interleukin-1beta Is a Negative Transcriptional Regulator of Alphal-Adrenergic Induced Gene Expression in Cultured Cardiac Myocytes. J. Biol. Chem. 271 (35), 2113421141. doi: 10.1074/jbc.271.35.21134

Pinsky, D. J., Aji, W., Szabolcs, M., Athan, E. S., Liu, Y., Yang, Y. M., et al. (1999). Nitric Oxide Triggers Programmed Cell Death (Apoptosis) of Adult Rat Ventricular Myocytes in Culture. Am. J. Physiol. 277 (3 Pt 2), H1189H1199. doi: 10.1152/ajpheart.1999.277.3.H1189

Pizzi, T. (1953). Sobre El Problema De Las Formas Delgadas De "Trypanosoma Cruzi" (Comunicacion Preliminar). Boletín Inf Parasitol Chilenas 8, 5.

Postan, M., Arnaiz, M. R., and Fichera, L. E. (1999). Myocardial Cell Response to Trypanosoma Cruzi Infection. Medicina 59 Suppl 2, 57-62.

Prager, R. (1952). Estabilization De La Virulencia De Una Cepa De Trypanosoma Cruzi Por Pasage Seriado En Ratones De Constitucion Genetica Uniforme: Analisis Quantitativo Del Curso De La Infeccion. Biologica 16 (17), 9.

Reis, M. M., Higuchi Mde, L., Benvenuti, L. A., Aiello, V. D., Gutierrez, P. S., Bellotti, G., et al. (1997). An In Situ Quantitative Immunohistochemical Study of Cytokines and IL-2R+ in Chronic Human Chagasic Myocarditis: Correlation With the Presence of Myocardial Trypanosoma Cruzi Antigens. Clin. Immunol. Immunopathol 83 (2), 165-172. doi: 10.1006/clin.1997.4335

Rodrigues, M. M., Oliveira, A. C., and Bellio, M. (2012). The Immune Response to Trypanosoma Cruzi: Role of Toll-Like Receptors and Perspectives for Vaccine Development. J. Parasitol Res. 2012, 507874. doi: 10.1155/2012/507874
Silva, G. K., Costa, R. S., Silveira, T. N., Caetano, B. C., Horta, C. V., Gutierrez, F. R., et al. (2013). Apoptosis-Associated Speck-Like Protein Containing a Caspase Recruitment Domain Inflammasomes Mediate IL-1beta Response and Host Resistance to Trypanosoma Cruzi Infection. J. Immunol. 191 (6), 3373-3383. doi: 10.4049/jimmunol.1203293

Silva, G. K., Gutierrez, F. R., Guedes, P. M., Horta, C. V., Cunha, L. D., Mineo, T. W., et al. (2010). Cutting Edge: Nucleotide-Binding Oligomerization Domain 1-Dependent Responses Account for Murine Resistance Against Trypanosoma Cruzi Infection. J. Immunol. 184 (3), 1148-1152. doi: 10.4049/jimmunol. 0902254

Silva, J. S., Morrissey, P. J., Grabstein, K. H., Mohler, K. M., Anderson, D., and Reed, S. G. (1992). Interleukin 10 and Interferon Gamma Regulation of Experimental Trypanosoma Cruzi Infection. J. Exp. Med. 175 (1), 169-174. doi: $10.1084 /$ jem.175.1.169

Silva, L. H. P., and Nussenzweig, V. (1953). Sobre Uma Cepa De Trypanosoma Cruzi Altamente Virulenta Para O Camundongo Branco. Folia Clin. Biol. 20, 13.

Silva, J. S., Twardzik, D. R., and Reed, S. G. (1991). Regulation of Trypanosoma Cruzi Infections In Vitro and In Vivo by Transforming Growth Factor Beta (TGF-Beta). J. Exp. Med. 174 (3), 539-545. doi: 10.1084/jem.174.3.539

Silva, J. S., Vespa, G. N., Cardoso, M. A., Aliberti, J. C., and Cunha, F. Q. (1995). Tumor Necrosis Factor Alpha Mediates Resistance to Trypanosoma Cruzi Infection in Mice by Inducing Nitric Oxide Production in Infected Gamma Interferon-Activated Macrophages. Infect Immun. 63 (12), 4862-4867. doi: 10.1128/iai.63.12.4862-4867.1995

Sousa, G. R., Gomes, J. A., Fares, R. C., Damasio, M. P., Chaves, A. T., Ferreira, K. S., et al. (2014). Plasma Cytokine Expression Is Associated With Cardiac Morbidity in Chagas Disease. PloS One 9 (3), e87082. doi: 10.1371/ journal.pone. 0087082

Teixeira, M. M., Gazzinelli, R. T., and Silva, J. S. (2002). Chemokines, Inflammation and Trypanosoma Cruzi Infection. Trends Parasitol 18 (6), 262-265. doi: 10.1016/S1471-4922(02)02283-3

Teston, A. P., Monteiro, W. M., Reis, D., Bossolani, G. D., Gomes, M. L., de Araujo, S. M., et al. (2013). In Vivo Susceptibility to Benznidazole of Trypanosoma Cruzi Strains From the Western Brazilian Amazon. Trop. Med. Int. health: TM IH 18 (1), 85-95. doi: 10.1111/tmi.12014

Truyens, C., Torrico, F., Lucas, R., De Baetselier, P., Buurman, W. A., and Carlier, Y. (1999). The Endogenous Balance of Soluble Tumor Necrosis Factor Receptors and Tumor Necrosis Factor Modulates Cachexia and Mortality in Mice Acutely Infected With Trypanosoma Cruzi. Infect Immun. 67 (11), 55795586. doi: 10.1128/IAI.67.11.5579-5586.1999

Zingales, B. (2018). Trypanosoma Cruzi Genetic Diversity: Something New for Something Known About Chagas Disease Manifestations, Serodiagnosis and Drug Sensitivity. Acta tropica 184, 38-52. doi: 10.1016/j.actatropica.2017.09.017

Zingales, B., Andrade, S. G., Briones, M. R., Campbell, D. A., Chiari, E., Fernandes, O., et al. (2009). A New Consensus for Trypanosoma Cruzi Intraspecific Nomenclature: Second Revision Meeting Recommends TcI to TcVI. Memorias do Instituto Oswaldo Cruz 104 (7), 1051-1054. doi: 10.1590/ S0074-02762009000700021

Zingales, B., Miles, M. A., Campbell, D. A., Tibayrenc, M., Macedo, A. M., Teixeira, M. M., et al. (2012). The Revised Trypanosoma Cruzi Subspecific Nomenclature: Rationale, Epidemiological Relevance and Research Applications. Infect Genet. Evol: J. Mol. Epidemiol. Evol Genet. Infect. Dis. 12 (2), 240-253. doi: 10.1016/j.meegid.2011.12.009

Conflict of Interest: The authors declare that the research was conducted in the absence of any commercial or financial relationships that could be construed as a potential conflict of interest.

Copyright (๑) 2021 Queiroga, Pereira, Silva, Andrade, Araújo Júnior, Brito, Galvão, Câmara, Nascimento and Guedes. This is an open-access article distributed under the terms of the Creative Commons Attribution License (CC BY). The use, distribution or reproduction in other forums is permitted, provided the original author(s) and the copyright owner(s) are credited and that the original publication in this journal is cited, in accordance with accepted academic practice. No use, distribution or reproduction is permitted which does not comply with these terms. 